\title{
The older dental patient - who cares?
}

\author{
P. H. Hellyer ${ }^{1}$
}
- Asks what the dental expectations of the so-called 'heavy metal generation' are.
- Reviews attitudes to ageing found in English literature.
- Suggests a way forward to support these dental expectations, amid current attitudes to older people.

\begin{abstract}
People in the United Kingdom are living for longer and taking their natural dentitions with them into old age. If the dental profession as a whole is to be prepared to support the care of older people, a clear understanding of what it is to be old will be needed. But with much talk of this heavy metal generation having complex restorative needs, the technical aspects of care are being emphasised. This paper suggests that there may be more basic needs to be addressed.
\end{abstract}

\section{INTRODUCTION}

The population of the UK is ageing. Over the last 25 years the percentage of the population aged 65 and over increased from $15 \%$ in 1983 to $16 \%$ in 2008, an increase of 1.5 million people in this age group. Over the same period, the percentage of the population aged 16 and under decreased from $21 \%$ to $19 \%$. This trend is projected to continue. ${ }^{1}$ By 2033, 23\% of the population will be aged 65 and over compared to $18 \%$ aged 16 or younger. ${ }^{1}$

The UK Adult Dental Health Survey $(2009)^{2}$ shows a continuing decline in the percentage of people with no teeth. The proportion of adults who have lost all their natural teeth has decreased since 1978, when the first UK Adult Dental Health Survey was carried out, from 30\% in 1978 to $6 \%$ in 2009.

In addition to the decline in edentulousness, the 1998 survey $^{3}$ showed that older people had larger increases in the average number of teeth present. Those aged 55 years and over had an average of 1.8 more teeth in 1998 than in 1988. The comparable increase for those aged 16 to 24 years was 0.3 teeth. It can be seen therefore that the population of the UK is changing. In

${ }^{1}$ Clinical teacher, King's College London Dental Institute, Correspondence to: Mr Paul Hellyer, University of Portsmouth Dental Academy, Hampshire Terrace, Portsmouth, P01 20G

Email:paul.hellyer@port.ac.uk

\section{Refereed Paper}

Accepted 15 June 2011

DOI: $10.1038 /$ sj.bdj.2011.618

${ }^{\circ}$ British Dental Journal 2011; 211: 109-111 the future there will be greater numbers of older people and those older people will have more natural teeth retained.

These older people's teeth are more likely to have periodontal attachment loss. The 1998 survey showed that the proportion of dentate adults with some loss of attachment increased from 14\% among those aged 16 to 24 years to $85 \%$ of those aged 65 and over. The root surfaces of teeth with attachment loss were found to be particularly prone to dental caries. Forty-three percent of people aged 65 years and over had teeth with restored root surfaces.

Attitudes, too, are changing. Most older people want to keep their teeth The survey showed that $81 \%$ expected to retain some of these for their lifetime; 61\% thought that the need for complete replacement of their teeth by dentures would be very upsetting and 27\% found the idea of partial replacement by dentures very upsetting. It has been suggested that negative dental attitudes among older patients are carried forwards from childhood, and reinforced by subsequent experiences at the dentist. ${ }^{4}$ Conversely it would be reasonable to assume that those with positive attitudes to dentistry and oral health will also carry these into old age.

Clearly therefore, dental care for the older adult will assume greater significance over the next 25 years. Numbers of older adults will increase, these adults will retain more of their natural teeth than previous generations, they will expect to do so and will less likely to accept dentures as an alternative in the future. It can be assumed therefore that in the next 20-30 years, older adults will expect to keep their teeth for life.

\section{OLD AGE}

Historically, tooth loss was an accepted part of old age. 'The grinders cease because they are few' wrote the author of Ecclesiastes 3,000 years ago. ${ }^{5}$ But then, old age was also defined in terms of loss of other faculties also - shaking limbs, blindness, and loss of hearing. Centuries later, Shakespeare uses similar images to define old age - 'second childishness, ... sans teeth, sans eyes ...... And even in the 1970s, Philip Larkin describes an equally negative picture of old age:

'...And these are the first signs:

'Not knowing how, not hearing who, the power

'Of choosing gone. Their looks show that they're for it:

'Ash hair, toad hands, prune face dried into lines..."

In the same decade, Simone de Beauvoir states that one of the characteristics of old age is that "the teeth drop out."

But we know now that tooth loss is the sequelae of oral pathology - largely dental caries and periodontal diseases. But do we have any greater understanding of what it is to be 'old'?

Many of the other characteristics with which older people are stigmatised are pathological - the shaking limbs of 
Parkinson's disease, the second childishness of Alzheimer's disease, for instance. The giants of geriatric medicine - incontinence, instability, immobility and intellectual impairment ${ }^{9}$ - are well recognised.

But old age is not an illness. One definition states that ageing is "the gradual development of changes in structure and function that are not due to preventable disease or trauma, and that are associated with decreased functional capacity and an increased probability of death. ${ }^{9}$

Simone de Beauvoir describes old age as 'a dreaded decline ... in complete conflict with the manly or womanly ideal cherished by the young. Our attitude, she says, is 'to reject (old age) as it is summed up by the words decrepitude, ugliness and illhealth: ${ }^{8}$ Clearly this is a younger person's image of what it is like to be old. Unlike living through childhood or the angst of the teenage years, old age is not to be experienced until the time comes. The perception of old age is from the outside and coloured by experiences of others a parent with dementia, or memories of visits to a grandparent in a nursing home.

Succinctly, Proust says that 'old age, [which] of all the realities, is perhaps the one of which we retain a purely abstract notion for the longest time'. ${ }^{10}$ A concern - or even fear - of our unknown future may go some way to explain the way in which older people are treated by society. One parliamentary report suggests that ageism is rife within the National Health Service and concludes that our culture needs to move to 'one where the needs of the individual older person are at the heart of healthcare services'.1 A more recent report by the Health Services Ombudsman presents a picture of "NHS provision that is failing to respond to the needs of older people with care and compassion and to provide even the most basic standards of care. ${ }^{12}$

\section{TEETH FOR LIFE?}

As dentists and dental care professionals (DCPs) we should be different. Dentists and the allied professions will see increasing numbers of older patients in the future. McHarg and Kay ${ }^{13}$ suggest that there will be many with complex oral care needs, as the heavily restored dentitions of the baby boom generation of the 1940s and 1950s reach old age. It may well be the case that the independent, still-caring-forthemselves older patient will fall into this category. It is likely, however, that many more will need support with oral hygiene and other preventive measures as the decreased functional capacity of old age occurs, before any extensive restorative treatment is undertaken.

However, the increasingly dependent elderly and those with pathology associated with old age will most probably not be appropriately treated with extensive restorative treatment. Most of this category of older patient will require oral hygiene support, topical fluoride applications and sensible dietary advice to prevent any deterioration of their oral health.

A recent paper concerning the undergraduate curriculum in gerodontology for dental students ${ }^{14}$ concludes with this statement:

'The demography of ageing in European countries is now generally well known, but the impact on dental services of the increasing numbers of older people and particularly the old elderly has not been reflected in the dental curriculum. Few practicing dentists have received any formal education on the significance of age and ageing for their patients. They are therefore poorly prepared to learn from CPD even when this becomes more widely available. The case presented here indicates the urgent need for review of gerodontology in the dental undergraduate curriculum.'

The General Dental Council also recognises the importance of gerodontology to the training of dental hygienists and therapists. ${ }^{15}$ They propose that they should:

- Be competent to provide dental hygiene care for the older adult

- Be familiar with the physiology of ageing and the management of problems associated with the care of the older adult

- Be familiar with the presentation of oral and dental diseases and diseases in the older adult.

Previously published curriculum requirements for gerodontology are similar but refer specifically to 'psychological and social factors' in the older patient and the avoidance of 'stereotyping'. A limited range of specific conditions are also listed. ${ }^{16}$
Clearly both dentists and DCPs have a role to play in the care of the older patient. However, care for the older patient should be patient centred, and not focused on procedures alone and will, consequently, be time consuming. The intra-oral procedures needed to provide oral care for older people - giving oral hygiene education, application of topical fluoride, dietary advice, some simple restoration of root caries - will have been taught at different times throughout dental training, whether for dentists or DCPs. None are particularly complex in themselves and are clearly within the remit of dental hygienists and therapists. However, a clear and thorough understanding of the ageing process is needed if dental professionals are to be able to treat older patients with dignity and compassion and to assist them in their stated objective of 'keeping their teeth for life'.

In view of the changing demographics, I believe there is a need for dental hygienists and therapists in particular to be trained specifically in the needs of older patients, to be trained to understand the processes, both physiological and pathological which accompany the ageing process and the social consequences of both, in order for those patients who wish to retain their teeth for life to be given as great an opportunity as possible to do so.

Indeed, I suggest there is a strong case for the development of a specialism within the DCP remit to cater for the increasing numbers of motivated, dentate older people to come.

1. Office for National Statistics. Ageing: Fastest increase in the 'oldest old.' http://www.statistics.gov. uk/cci/nugget.asp?lD=949 (accessed 16 May 2011).

2. NHS Information Centre. Adult Dental Health Survey - 2009, First Release. 8 December 2010. http://www.ic.nhs.uk/default.asp?sID $=11725774141$ 29\&tsPublication $\mid \mathrm{D}=1291651947164$ \&tsDoc $\mid \mathrm{D}=6622$ (accessed 18 May 2011)

3. Office for National Statistics. Adult Dental Health Survey: Oral Health in the United Kingdom 1998. http://www.statistics.gov.uk/downloads/theme_ health/DHBulletinNew.pdf (accessed 18 May 2011).

4. Borreani $E_{1}$ Jones $K_{1}$ Scambler $S$, Gallagher $E$. Informing the debate on oral health care for older people; a qualitative study of older people's views on oral health and oral health care. Gerodontology 2010; 27: 11-18.

5. International Bible Society. Ecclesiastes 12v3. The Bible (New International Version). 1999.

6. Shakespeare W. As you like it. Act 2 Scene 7.

7. Larkin P. The old fools. In Collected poems. The Marvel Press, 2003.

8. de Beauvoir S. Old age. London: Penguin Books, 1988.

9. Greenwood M, Jay R H, Meechan J G. General medicine and surgery for dental practitioners. Part 1 - the older patient. Br Dent J 2010; 208: 339-342. 
10. Quoted in de Beauvoir S. Old age. London: Penguin Books, 1988.

11. House of Lords, House of Commons, Joint Committee on Human Rights. The human rights of older people in healthcare. Eighteenth Report of Session 2006-07. Volume 1 - Report and Formal Minutes. 14 August 2007. http://www. publications.parliament.uk/pa/jt200607/jtselect/ jtrights/156/156i.pdf (accessed 16 February 2011).
12. Parliamentary and Health Service Ombudsman. Care and compassion? Report of the Health Service Ombudsman on ten investigations into NHS care of older people. http://www.ombudsman.org. uk/_data/assets/pdf_file/0016/7216/Care-andCompassion-PHSO-0114web.pdf (accessed 16 February 2011).

13. McHarg J, Kay E. Designing a dental curriculum for the twenty-first century. Br Dent J 2009;
207: 493-497

14. Kossioni A, Vanobbergen J, Newton J, Müller F, Heath R. European College of Gerodontology: undergraduate curriculum guidelines in Gerodontology. Gerodontology 2009; 26: 165-171.

15. General Dental Council. Developing the dental team 2nd ed - interim. London: GDC, 2009.

16. General Dental Council. Developing the dental team London: GDC, 2004. 